\title{
Adubação com fósforo e potássio para produção e qualidade de sementes de soja
}

\author{
Felipe Batistella Filho(1), Manoel Evaristo Ferreira(1), Roberval Daiton Vieira ${ }^{(2)}$, \\ Mara Cristina Pessôa da Cruz ${ }^{(1)}$, Maria Aparecida Pessôa da Cruz Centurion(2), \\ Thiago de Barros Sylvestre(1) e Juan Gabriel Cristhoffer Lopes Ruiz(1)
}

\begin{abstract}
(1)Universidade Estadual Paulista (Unesp), Faculdade de Ciências Agrárias e Veterinárias, Departamento de Solos e Adubos, Via de Acesso Prof. Paulo Donato Castellane, s/no, CEP 14884-900 Jaboticabal, SP. E-mail: batistellafilho@yahoo.com.br, evaristo@fcav.unesp.br, mcpcruz@fcav.unesp.br, thiagosylvestre@hotmail.com, juanboifran@hotmail.com (2)Unesp, Departamento de Produção Vegetal. E-mail: rdvieira@fcav.unesp.br, cidinha@fcav.unesp.br
\end{abstract}

Resumo - O objetivo deste trabalho foi avaliar os efeitos da adubação com fósforo e potássio na produção e na qualidade de sementes de soja. Foram realizados experimentos em dois anos agrícolas, em delineamento de blocos ao acaso, em arranjo fatorial 5x3, com cinco doses de fósforo $\left(0,40,80,120\right.$ e $160 \mathrm{~kg} \mathrm{ha}^{-1} \mathrm{de}_{2} \mathrm{O}_{5}$ como superfosfato triplo), três de potássio $\left(0,50\right.$ e $100 \mathrm{~kg} \mathrm{ha}^{-1}$ de $\mathrm{K}_{2} \mathrm{O}$ como cloreto de potássio) e quatro repetições. Foram avaliados: produtividade, número de sementes por planta, número de vagens por planta, peso de mil sementes, germinação, vigor (envelhecimento acelerado, condutividade elétrica e lixiviação de potássio), e teores de $\mathrm{P}$ e $\mathrm{K}$ na folha e na semente. A produtividade, o peso de mil sementes e a produção de vagens e de grãos por planta aumentaram linearmente com a adubação fosfatada. $\mathrm{O}$ aumento na produtividade foi de $17,6 \%$, no primeiro ano, e de $39,7 \%$ no segundo. As doses de $\mathrm{P}$, no entanto, não interferiram na germinação e no vigor das sementes. A adubação potássica não altera a produtividade nem a concentração de $\mathrm{K}$ nas sementes, mas pode melhorar a germinação, sem interferir no vigor.

Termos para indexação: Glycine max, adubação fosfatada, adubação potássica, germinação, nutrição mineral, vigor.

\section{Phosphorus and potassium fertilization for yield and quality of soybean seeds}

\begin{abstract}
The objective of this work was to evaluate the effects of phosphorus and potassium fertilization on the yield and quality of soybean seeds. Experiments were carried out in two growing seasons, in a randomized complete block design, in a $5 \times 3$ factorial arrangement with five levels of phosphorus $(0,40,80,120$, and $160 \mathrm{~kg} \mathrm{ha}^{-1} \mathrm{P}_{2} \mathrm{O}_{5}$ as triple superphosphate), three of potassium $\left(0,50\right.$, and $100 \mathrm{~kg} \mathrm{ha}^{-1} \mathrm{~K}_{2} \mathrm{O}$ as potassium chloride), and four replicates. The following were evaluated: yield, number of seeds per plant, number of pods per plant, weight of a thousand seeds, germination, vigor (accelerated ageing, electrical conductivity, and potassium leaching), and $\mathrm{P}$ and $\mathrm{K}$ contents in leaf and seed. Yield, weight of a thousand seeds, and pod and seed yield per plant increased linearly with P fertilization. The increase in yield was $17.6 \%$ in the first year and $39.7 \%$ in the second. However, P levels did not affect seed germination and vigor. Potassium fertilization do not influence yield or K concentration in the seeds, but may improve germination, without interfering in vigor.

Index terms: Glycine max, phosphate fertilization, potassium fertilization, germination, mineral nutrition, vigor.
\end{abstract}

\section{Introdução}

Os componentes de produção da soja [Glycine $\max (\mathrm{L}$.$) Merrill], como número de vagens por planta,$ número de sementes por vagem e peso específico das sementes, são bastante influenciados pelas condições edafoclimáticas e pelo manejo químico do solo (Peixoto et al., 2000), especialmente pelas adubações fosfatada e potássica. Em leguminosas, a deficiência de $\mathrm{P}$ diminui o potencial de rendimento pela menor produção de flores e de vagens, maior taxa de aborto destas estruturas e pela produção de sementes com menor massa (Ventimiglia et al., 1999; Zucareli et al., 2006; Oliveira Júnior et al., 2011). Já a deficiência de $\mathrm{K}$ pode ocasionar a produção de sementes mais leves, o que, além de afetar o rendimento da cultura, pode 
resultar em plantas mais baixas e menos produtivas no ciclo subsequente (Pádua et al., 2010). Serafim et al. (2012) observaram aumento no rendimento e no peso específico das sementes, em resposta à adubação com esse nutriente.

Nas sementes, aproximadamente $75 \%$ do P ocorre na forma de ácido fítico, que pode fornecer $\mathrm{P}$ na fase inicial da germinação (Raboy, 2009). Os teores de $\mathrm{P}$ em sementes de soja variam com a cultivar e o manejo químico do solo (Olibone \& Rosolem, 2010). Já o suprimento adequado de K é importante para a viabilidade das sementes, uma vez que esse nutriente tem diversas funções no metabolismo das plantas, como controle da absorção de água, ativação enzimática, crescimento dos tecidos meristemáticos, síntese de proteínas e carboidratos, translocação de assimilados e abertura e fechamento dos estômatos (Veiga et al., 2010). Os teores de $\mathrm{K}$ na semente comumente aumentam com o seu fornecimento pela adubação, tendo sido observadas respostas a teores de $\mathrm{K}$ no solo de até 3,0 $\mathrm{mmol}_{\mathrm{c}} \mathrm{dm}^{-3}$ (Sale \& Campbell, 1986; Serafim et al., 2012).

Entretanto, os efeitos das adubações fosfatada e potássica na germinação e no vigor de sementes da soja ainda não são conclusivos. Constatou-se, por exemplo, aumento no vigor com a adubação fosfatada, no teste de primeira contagem de germinação, o que, no entanto, não foi observado nos testes de envelhecimento acelerado, índice de velocidade de emergência e matéria seca de plântulas (Vieira et al., 1987). No caso da adubação com K, Veiga et al. (2010), ao utilizar os testes de germinação e do envelhecimento acelerado, não verificaram efeito da aplicação de até $200 \mathrm{~kg} \mathrm{ha}^{-1}$ de $\mathrm{K}_{2} \mathrm{O}$ na qualidade de sementes de soja, em solo com teor médio de K. Toledo et al. (2011), no entanto, relataram que a aplicação de até $100 \mathrm{~kg} \mathrm{ha}^{-1}$ de $\mathrm{K}_{2} \mathrm{O}$ resulta em aumento na germinação de sementes sem, contudo, afetar o vigor, avaliado pelo teste da condutividade elétrica. Portanto, o teste de vigor empregado pode influenciar na avaliação dos efeitos das adubações fosfatada e potássica, e a relação entre os resultados desses testes e as concentrações dos nutrientes na semente nem sempre é observada (Marcos Filho \& Vieira, 2009).

O objetivo deste trabalho foi avaliar o efeito da adubação com fósforo e potássio na produção e na qualidade de sementes de soja.

\section{Material e Métodos}

Os experimentos foram realizados em campo, nas safras 2009/2010 e 2010/2011, no Município de Jaboticabal, SP $\left(21^{\circ} 15^{\prime} 12^{\prime \prime} \mathrm{S}, 48^{\circ} 18^{\prime} 58^{\prime \prime} \mathrm{W}\right.$, a $595 \mathrm{~m}$ de altitude).

Durante a condução dos experimentos, as temperaturas variaram entre 31,5 e $19,6^{\circ} \mathrm{C}$, na safra $2009 / 2010$, e entre 31,7 e $19,2^{\circ} \mathrm{C}$, na safra $2010 / 2011$. O total de chuva acumulado foi de 988 e de $1.231 \mathrm{~mm}$ (Figura 1), para as safras 2009/2010 e 2010/2011, respectivamente (Universidade Estadual Paulista Júlio de Mesquita Filho, 2012). O solo da área, de acordo com o Sistema Brasileiro de Classificação de Solos (Santos, 1998), é Latossolo Vermelho distrófico típico (Centurion, 1998).

Amostras compostas de solo foram coletadas nas camadas de 0 a $0,2 \mathrm{~m}$ e de 0,2 a $0,4 \mathrm{~m}$, e submetidas à análise química segundo Raij et al. (2001), nas safras 2009/2010 e 2010/2011.

Utilizou-se o delineamento experimental de blocos ao acaso, em arranjo fatorial $5 \times 3$, com quatro repetições. Foram avaliadas as doses de $0,40,80,120$ e $160 \mathrm{~kg} \mathrm{ha}^{-1}$ de $\mathrm{P}_{2} \mathrm{O}_{5}$ (equivalentes a $0,50,100,150$ e $200 \%$ da dose recomendada, respectivamente) e de 0,50 e $100 \mathrm{~kg} \mathrm{ha}^{-1}$ de $\mathrm{K}_{2} \mathrm{O}$ (equivalentes a 0, 100 e $200 \%$ da dose recomendada). As doses referenciais foram baseadas nas recomendações de Raij et al. (1997), tendo-se considerado os resultados da análise química do solo (Tabela 1) e a meta de produtividade de 2,5-2,9 $\mathrm{Mg} \mathrm{ha}^{-1}$. As fontes de fósforo e de potássio foram o superfosfato triplo e o cloreto de potássio, respectivamente.

A cultivar de soja utilizada foi a MG/BR 46 (Conquista), que apresenta período juvenil longo, o

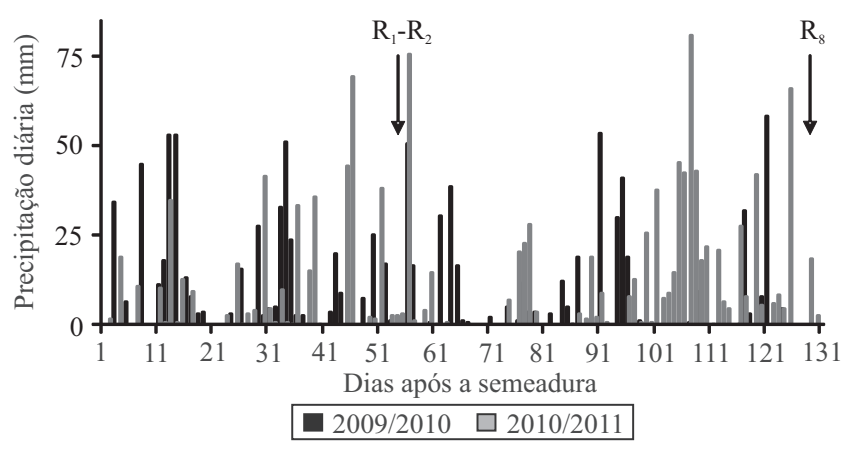

Figura 1. Precipitação diária no período de condução dos experimentos, nas safras 2009/2010 e 2010/2011. 
que a torna recomendável para quase todos os estados brasileiros, em razão da sua alta adaptabilidade. Essa cultivar é bastante cultivada e estudada na região de Jaboticabal (Beutler et al., 2007; Nunes et al., 2010).

As parcelas foram constituídas por cinco linhas de $3 \mathrm{~m}$ de comprimento, com espaçamento de $0,45 \mathrm{~m}$, o que resultou em área total de $6,75 \mathrm{~m}^{2}$. A área útil foi representada pelas três linhas centrais, tendo-se desprezado $0,5 \mathrm{~m}$ de cada extremidade, o que totalizou $2,7 \mathrm{~m}^{2}$.

O preparo do solo foi feito com uma aração e duas gradagens. A calagem foi feita de acordo com as recomendações de Raij et al. (1997), tendo-se empregado calcário agrícola ultrafino, com PRNT de $100 \%$, que foi distribuído uniformemente e incorporado com grade aradora. Em seguida, foi feito o controle preventivo de plantas daninhas com a aplicação de trifluralina, que foi incorporada com grade, para evitar perdas por volatilização e fotodecomposição.

A área foi sulcada e estaqueada, e os fertilizantes fosfatado e potássico foram distribuídos manualmente no sulco e cobertos com pequena quantidade de solo. Em seguida, foi feita a distribuição manual de aproximadamente 30 sementes por metro. Após a emergência das plântulas, no estágio fenológico $\mathrm{V}_{2}$, foi feito o desbaste, tendo-se estabelecido população equivalente a 300 mil plantas por hectare, que correspondeu a 13,5 plantas por metro, no espaçamento de $0,45 \mathrm{~m}$. Posteriormente ao desbaste, foi feita a adubação com $45 \mathrm{~kg} \mathrm{ha}^{-1}$ de S (Raij et al., 1997) na forma de gesso agrícola, aplicado em cobertura.

Para o controle das plantas daninhas, além da aplicação do herbicida em pré-plantio, foram feitas capinas quinzenais até os estádios fenológicos $\mathrm{V}_{5}-\mathrm{V}_{7}$, o que ocorreu, aproximadamente, aos 50 dias após a semeadura. Para o controle das doenças, sobretudo da ferrugem asiática, foram feitas aplicações preventivas e alternadas de fungicidas, do início do florescimento (estádios fenológicos $\mathrm{R}_{1}-\mathrm{R}_{2}$ ) até o início da senescência das folhas (estádios fenológicos $\mathrm{R}_{6}-\mathrm{R}_{7}$ ). $\mathrm{O}$ controle de pragas, em especial dos percevejos da soja, foi feito a partir do início da formação de vagens, com os inseticidas recomendados para a cultura, que foram aplicados alternadamente a cada quinzena, até o final do ciclo.

No início do florescimento, foi feita amostragem para determinação dos teores de nutrientes nas folhas, tendo-se coletado 30 folhas com pecíolo por parcela (Raij et al., 1997). As amostras foram lavadas e secas em estufa com circulação forçada de ar, a $65^{\circ} \mathrm{C}$, até peso constante, para serem posteriormente moídas e analisadas.

A colheita foi feita manualmente no estádio $R_{8}$ (Fehr \& Caviness, 1977). A linha central foi destinada à obtenção de sementes, e as vagens foram retiradas e debulhadas manualmente para evitar a ocorrência de danos mecânicos. As plantas das duas linhas adjacentes foram trilhadas mecanicamente. As sementes foram limpas e armazenadas em câmara fria e seca, com temperatura média de $10^{\circ} \mathrm{C}$ e umidade relativa do ar em torno de $50 \%$, para manter a qualidade fisiológica. $\mathrm{O}$ número de vagens por planta e a quantidade de sementes por planta foram determinados com amostragem de dez plantas por parcela (Peixoto et al., 2000). O peso de mil sementes foi avaliado conforme Regras para análise de sementes (2009), tendo-se pesado oito repetições de 100 sementes. Tanto a produtividade quanto o peso de mil sementes foram corrigidos para $13 \%$ de teor de água.

Tabela 1. Atributos químicos do solo, nas safras 2009/2010 e 2010/2011.

\begin{tabular}{|c|c|c|c|c|c|c|c|c|c|c|}
\hline \multirow[t]{2}{*}{ Camada (m) } & $\mathrm{pH}$ & $\mathrm{MO}$ & P resina & $\mathrm{K}$ & $\mathrm{Ca}$ & $\mathrm{Mg}$ & $\mathrm{H}+\mathrm{Al}$ & SB & CTC & \multirow{2}{*}{$\begin{array}{l}\mathrm{V} \\
(\%)\end{array}$} \\
\hline & $\mathrm{CaCl}_{2}$ & $\left(\mathrm{~g} \mathrm{dm}^{-3}\right)$ & $\left(\mathrm{mg} \mathrm{dm}^{-3}\right)$ & --- & - & --- $(n$ & $\left(m^{-3}\right)--$ & 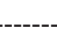 & ---- & \\
\hline & \multicolumn{10}{|c|}{ Safra 2009/2010 } \\
\hline $0,0-0,2$ & 5,0 & 21 & 6 & 1,8 & 17 & 7 & 28 & 26 & 54 & 48 \\
\hline \multirow[t]{2}{*}{$0,2-0,4$} & 4,8 & 16 & 5 & 1,0 & 12 & 5 & 31 & 18 & 49 & 37 \\
\hline & \multicolumn{10}{|c|}{ Safra 2010/2011 } \\
\hline $0,0-0,2$ & 4,9 & 16 & 6 & 1,6 & 11 & 7 & 28 & 20 & 48 & 41 \\
\hline $0,2-0,4$ & 4,6 & 14 & 3 & 1,3 & 9 & 5 & 28 & 15 & 43 & 35 \\
\hline
\end{tabular}


A germinação foi determinada por meio do teste padrão de germinação (Regras para análise de sementes, 2009). No teste do envelhecimento acelerado, as sementes foram mantidas a $42^{\circ} \mathrm{C}$, por 48 horas e, em seguida, submetidas ao teste de germinação (Baalbaki et al., 2009). Para medida da condutividade elétrica, amostras de 50 sementes foram embebidas em água deionizada e mantidas a $25^{\circ} \mathrm{C}$, por 24 horas (Vieira et al., 2008). No teste de lixiviação de potássio, amostras de 50 sementes foram imersas em $75 \mathrm{~mL}$ de água destilada, em copos de plástico, onde foram mantidas a $30^{\circ} \mathrm{C}$, durante $30 \mathrm{~min}$, tendo-se retirado $50 \mathrm{~mL}$ para determinação de $\mathrm{K}$ por fotometria de chama (Custódio \& Marcos Filho, 1997).

As concentrações de $\mathrm{P}$ e $\mathrm{K}$ nas folhas e nas sementes foram determinadas em extratos de digestão nítrico-perclórica, por colorimetria e por fotometria de chama, respectivamente.

Os dados de produção e da qualidade das sementes, de acordo com os tratamentos, foram avaliados por meio de análise de variância, seguida de comparação entre as médias pelo teste de Tukey, a 5 e $1 \%$ de probabilidade, e de análise de regressão. Os resultados das safras 2009/2010 e 2010/2011 foram analisados em separado, e ambos os experimentos foram comparados por meio de análise conjunta (Banzatto \& Kronka, 2006).

\section{Resultados e Discussão}

Em ambas as safras, a resposta da produtividade à adubação com $\mathrm{P}$ foi linear crescente. A aplicação de $160 \mathrm{~kg} \mathrm{ha}^{-1}$ de $\mathrm{P}_{2} \mathrm{O}_{5}$ proporcionou aumento de $435 \mathrm{~kg} \mathrm{ha}^{-1}$ de sementes, em 2009/2010, e de $1.069 \mathrm{~kg} \mathrm{ha}^{-1}$, em 2010/2011 - 17,6 e 39,7\% a mais do que o produzido no tratamento testemunha (Tabela 2 ). Esses resultados são condizentes com os aumentos lineares observados no peso de mil sementes (safra 2010/2011) e na produção de vagens e de grãos por planta (Tabela 3).

As sementes produzidas na safra 2010/2011, com a aplicação de $160 \mathrm{~kg} \mathrm{ha}^{-1}$ de $\mathrm{P}_{2} \mathrm{O}_{5}$, foram 3,1\% mais pesadas do que as do tratamento testemunha (Tabela 3). Esse resultado difere do obtido por Zucareli et al. (2006), que não observaram efeitos da adubação fosfatada no peso específico de sementes de feijão, com uso de até $150 \mathrm{~kg} \mathrm{ha}^{-1}$ de $\mathrm{P}_{2} \mathrm{O}_{5}$, em solo com teor muito baixo de $\mathrm{P}\left(6,0 \mathrm{mg} \mathrm{dm}^{-3}\right)$.

A adubação potássica não afetou a produtividade de sementes, em nenhuma das safras (Tabela 2), o que está relacionado aos teores médios de $\mathrm{K}$ no solo $\left(1,6\right.$ e $1,8 \mathrm{mmol}_{\mathrm{c}} \mathrm{dm}^{-3}$, para a primeira e a segunda safras, respectivamente). Nessa condição, a probabilidade de resposta à adubação com o nutriente é menor, embora a cultura da soja seja exigente e responsiva à adubação potássica (Foloni \& Rosolem, 2008; Serafim et al., 2012).

As produtividades médias nas safras 2009/2010 e 2010/2011 foram de 2.165 e $3.053 \mathrm{~kg} \mathrm{ha}^{-1}$, respectivamente. $\mathrm{O}$ menor rendimento na primeira safra resultou, em parte, da severidade da ferrugem asiática na região de Jaboticabal - apesar da aplicação preventiva de fungicidas - , e foi decorrente da menor produção de grãos e de vagens por planta (Tabelas 2 e 3). A menor precipitação

Tabela 2. Produtividade de sementes de soja, de acordo com doses de fósforo e potássio, nas safras $2009 / 2010$ e $2010 / 2011^{(1)}$.

\begin{tabular}{|c|c|c|c|c|c|c|c|c|c|c|c|}
\hline \multirow[t]{2}{*}{ Parâmetro } & \multicolumn{5}{|c|}{ Dose de $\mathrm{P}_{2} \mathrm{O}_{5}\left(\mathrm{~kg} \mathrm{ha}^{-1}\right)$} & \multirow[t]{2}{*}{ Equação } & \multirow[t]{2}{*}{$\mathrm{R}^{2}$} & \multicolumn{3}{|c|}{ Dose de $\mathrm{K}_{2} \mathrm{O}\left(\mathrm{kg} \mathrm{ha}^{-1}\right)$} & \multirow[t]{2}{*}{ Equação } \\
\hline & 0 & 40 & 80 & 120 & 160 & & & 0 & 50 & 100 & \\
\hline & & & & & & Safra 2009/2010 & & & & & \\
\hline Produtividade $\left(\mathrm{kg} \mathrm{ha}^{-1}\right)$ & 1.932 & 2.188 & 2.146 & 2.195 & 2.367 & $\mathrm{y}=2,1911 \mathrm{x}+1.990,29$ & $0,79 *$ & 2.168 & 2.197 & 2.132 & $\mathrm{y}=2.166^{\mathrm{ns}}$ \\
\hline Média $\left(\mathrm{kg} \mathrm{ha}^{-1}\right)$ & & & & & & $2.166 \mathrm{~B}$ & & & & & \\
\hline \multirow[t]{2}{*}{ CV $(\%)$} & & & & & & 13,1 & & & & & \\
\hline & & & & & & Safra 2010/2011 & & & & & \\
\hline$\underline{\text { Produtividade }\left(\mathrm{kg} \mathrm{ha}^{-1}\right)}$ & 2.438 & 2.880 & 3.172 & 3.274 & 3.507 & $y=6,3287 x+2.547,68$ & $0,95 * *$ & 3.153 & 3.097 & 2.913 & $\mathrm{y}=3.054^{\mathrm{ns}}$ \\
\hline Média $\left(\mathrm{kg} \mathrm{ha}^{-1}\right)$ & & & & & & $3.054 \mathrm{~A}$ & & & & & \\
\hline CV $(\%)$ & & & & & & 17,0 & & & & & \\
\hline
\end{tabular}

Pesq. agropec. bras., Brasília, v.48, n.7, p.783-790, jul. 2013

DOI: 10.1590/S0100-204X2013000700011 
observada em 2009/2010 (Figura 1) também pode ter contribuído para esse resultado (total de $988 \mathrm{~mm}$, em comparação à precipitação de $1.231 \mathrm{~mm}$, em 2010/2011).

A diferença no peso de mil sementes observada entre as safras 2009/2010 e 2010/2011 (Tabela 3) também pode ter resultado da desfolha provocada pela ferrugem asiática e da menor ocorrência de chuvas na safra 2009/2010, que teriam colaborado para o menor acúmulo de matéria seca nas sementes, com consequente diminuição no peso específico. Quanto maior a intensidade da desfolha, menor é o peso das sementes produzidas (Parcianello et al., 2004). Além disso, a desfolha pode resultar em plantas com menor altura e menos produtivas (Pádua et al., 2010), especialmente para a cultura da soja.

A adubação fosfatada aumentou linearmente as concentrações de $\mathrm{P}$, tanto na folha quanto nas sementes (Tabela 4). Olibone \& Rosolem (2010) também constataram aumento na concentração de $\mathrm{P}$ em sementes de soja com adubação fosfatada de até $80 \mathrm{~kg} \mathrm{ha}^{-1}$ de $\mathrm{P}_{2} \mathrm{O}_{5}$, porém a adubação potássica não influenciou os teores de K na semente (Tabela 4), o que contrariou a expectativa, uma vez que, em solos com disponibilidade de $\mathrm{K}$ menor do que 3,0 $\mathrm{mmol}_{\mathrm{c}} \mathrm{dm}^{-3}$, há relato de aumento nesses teores em resposta à adubação, em sementes de soja (Sale \& Campbell, 1986; Serafim et al., 2012). No entanto, a concentração de K na folha aumentou linearmente com adubação potássica, na safra 2009/2010, e variou de 20,53 a 22,88 $\mathrm{g} \mathrm{kg}^{-1}$, no intervalo entre 0 e $160 \mathrm{~kg} \mathrm{ha}^{-1}$ de $\mathrm{K}_{2} \mathrm{O}$.

Não foram observados efeitos sinérgicos ou antagônicos na absorção e acúmulo dos nutrientes nas folhas e sementes (Tabela 4).

As doses de $\mathrm{K}$ aumentaram linearmente a capacidade germinativa das sementes na safra 2009/2010. Como não houve efeito das doses de $\mathrm{K}$ sobre seus teores na semente, a capacidade germinativa destas não esteve associada às concentrações de $\mathrm{K}$ nos tecidos. Os valores, no entanto, ficaram todos acima de $90 \%$, o que caracteriza sementes de alta capacidade germinativa. Já na safra 2010/2011 a germinação média das sementes foi de $79,3 \%$ e não houve efeito da adubação com K, como também observado por Veiga et al. (2010). Em nenhuma das safras, o vigor das sementes foi alterado pela adubação potássica, independentemente do teste empregado na avaliação, resultado similar ao obtido por Veiga et al. (2010).

Quanto à adubação fosfatada, observou-se que ela não afetou a qualidade fisiológica das sementes produzidas, avaliada pelos testes de germinação e de vigor, apesar de ter aumentado a concentração de $\mathrm{P}$ nos tecidos (Tabela 5).

As sementes produzidas na safra 2009/2010 apresentaram qualidade fisiológica superior às

Tabela 3. Efeitos da aplicação de doses de fósforo e de potássio no número de vagens por planta, na quantidade de sementes por planta e no peso de mil sementes de soja, na safra 2009/2010 e 2010/2011 ${ }^{(1)}$.

\begin{tabular}{|c|c|c|c|c|c|c|}
\hline \multirow{2}{*}{$\begin{array}{l}\text { Dose } \\
\left(\mathrm{kg} \mathrm{ha}^{-1}\right)\end{array}$} & \multicolumn{2}{|c|}{ Vagens por planta } & \multicolumn{2}{|c|}{ Sementes por planta $(\mathrm{g})$} & \multicolumn{2}{|c|}{ Peso de mil sementes(g) } \\
\hline & $2009 / 2010$ & $2010 / 2011$ & $2009 / 2010$ & $2010 / 2011$ & $2009 / 2010$ & $2010 / 2011$ \\
\hline \multicolumn{7}{|l|}{$\overline{\mathrm{P}_{2} \mathrm{O}_{5}}$} \\
\hline 0 & 30,2 & 38,0 & 6,9 & 10,2 & 126,0 & 156,9 \\
\hline 40 & 35,1 & 42,7 & 8,1 & 12,2 & 125,6 & 157,7 \\
\hline 80 & 35,3 & 41,9 & 7,9 & 13,5 & 126,5 & 161,7 \\
\hline 120 & 36,7 & 47,6 & 8,2 & 14,2 & 126,4 & 163,4 \\
\hline 160 & 38,0 & 48,9 & 8,6 & 14,6 & 127,2 & 161,8 \\
\hline Equação & $\mathrm{y}=0,0428 \mathrm{x}+31,62$ & $\mathrm{y}=0,0663 \mathrm{x}+38,53$ & $y=0,0085 x+7,27$ & $\mathrm{y}=0,0268 \mathrm{x}+10,80$ & $\mathrm{y}=126,4^{\mathrm{ns}}$ & $\mathrm{y}=0,0389 \mathrm{x}+157,20$ \\
\hline $\mathrm{R}^{2}$ & $0,84^{* *}$ & $0,90^{* *}$ & $0,76 * *$ & $0,92 * *$ & - & $0,75^{*}$ \\
\hline \multicolumn{7}{|l|}{$\overline{\mathrm{K}_{2} \mathrm{O}}$} \\
\hline 0 & 34,8 & 44,8 & 7,9 & 13,2 & 126,2 & 159,4 \\
\hline 50 & 35,5 & 43,0 & 8,0 & 13,1 & 126,3 & 160,2 \\
\hline 100 & 34,9 & 43,8 & 7,9 & 12,5 & 126,6 & 161,3 \\
\hline Equação & $\mathrm{y}=35,0^{\mathrm{ns}}$ & $\mathrm{y}=43,8^{\mathrm{ns}}$ & $\mathrm{y}=7,9^{\mathrm{ns}}$ & $\mathrm{y}=12,9^{\mathrm{ns}}$ & $\mathrm{y}=126,4^{\mathrm{ns}}$ & $\mathrm{y}=160,3^{\mathrm{ns}}$ \\
\hline $\mathrm{R}^{2}$ & - & - & - & - & - & - \\
\hline Média & $35,0 \mathrm{~b}$ & $43,8 \mathrm{a}$ & $7,9 \mathrm{~b}$ & $12,9 \mathrm{a}$ & $126,4 \mathrm{~b}$ & $160,3 a$ \\
\hline
\end{tabular}

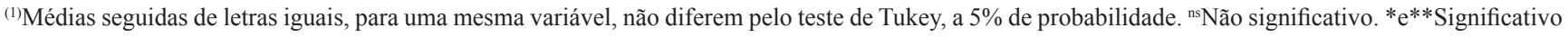
a 5 e $1 \%$ de probabilidade, respectivamente. Valores de F para a interação entres os fatores não foram significativos em nenhuma das safras. 
produzidas na safra 2010/2011, quando avaliadas pelos testes de germinação, envelhecimento acelerado e lixiviação de potássio (Tabela 5). $\mathrm{Na}$ fase de pré-colheita da safra 2010/2011, ocorreram chuvas intensas e frequentes, com elevação da umidade relativa do ar e diminuição da temperatura, fatores que atrasaram a secagem em campo e dificultaram a realização da colheita, o que diminuiu a qualidade fisiológica das sementes.
Os efeitos das adubações com $\mathrm{P}$ e $\mathrm{K}$ na produtividade e nos componentes de produção, assim como a predominante ausência de efeitos na qualidade fisiológica das sementes produzidas, avaliada pelos testes de germinação e vigor, confirmam que, em condições de menor disponibilidade de nutrientes, a planta diminui a produção sem comprometer a qualidade das sementes, de forma a garantir a perpetuação da espécie.

Tabela 4. Efeitos da aplicação de doses de fósforo e de potássio nas concentrações de P e K nas folhas e nas sementes de soja, na safra 2009/2010 e 2010/2011 ${ }^{(1)}$.

\begin{tabular}{|c|c|c|c|c|}
\hline \multirow{2}{*}{$\begin{array}{l}\text { Dose } \\
\left(\mathrm{kg} \mathrm{ha}^{-1}\right)\end{array}$} & \multicolumn{2}{|c|}{ Teor na folha } & \multicolumn{2}{|c|}{ Teor na semente } \\
\hline & $2009 / 2010$ & $2010 / 2011$ & $2009 / 2010$ & $2010 / 2011$ \\
\hline & \multicolumn{4}{|c|}{ Teor de $\mathrm{P}\left(\mathrm{g} \mathrm{kg}^{-1}\right)$} \\
\hline \multicolumn{5}{|l|}{$\mathrm{P}_{2} \mathrm{O}_{5}$} \\
\hline 0 & 1,75 & 1,83 & 4,42 & 4,07 \\
\hline 40 & 1,86 & 2,20 & 4,50 & 4,31 \\
\hline 80 & 2,12 & 2,39 & 4,60 & 4,55 \\
\hline 120 & 2,10 & 2,58 & 4,62 & 4,63 \\
\hline 160 & 2,03 & 2,62 & 4,74 & 4,74 \\
\hline Equação & $\mathrm{y}=0,0020 \mathrm{x}+1,82$ & $y=0,0049 x+1,93$ & $y=0,0019 x+4,43$ & $y=0,0042 x+4,12$ \\
\hline $\mathrm{R}^{2}$ & $0,62 *$ & $0,92 * *$ & $0,98 * *$ & $0,95^{* *}$ \\
\hline \multicolumn{5}{|l|}{$\overline{\mathrm{K}_{2} \mathrm{O}}$} \\
\hline 0 & 1,95 & 2,42 & 4,49 & 4,46 \\
\hline 50 & 1,93 & 2,27 & 4,65 & 4,44 \\
\hline 100 & 2,04 & 2,28 & 4,59 & 4,47 \\
\hline Equação & $\mathrm{y}=1,97^{\mathrm{ns}}$ & $\mathrm{y}=2,33^{\mathrm{ns}}$ & $\mathrm{y}=4,58^{\mathrm{ns}}$ & $\mathrm{y}=4,46^{\mathrm{ns}}$ \\
\hline $\mathrm{R}^{2}$ & - & - & - & - \\
\hline \multirow[t]{2}{*}{ Média } & $1,97 \mathrm{~b}$ & $2,33 \mathrm{a}$ & $4,58 \mathrm{a}$ & $4,46 b$ \\
\hline & \multicolumn{4}{|c|}{ Teor de $\mathrm{K}\left(\mathrm{g} \mathrm{kg}^{-1}\right)$} \\
\hline \multicolumn{5}{|l|}{$\mathrm{P}_{2} \mathrm{O}_{5}$} \\
\hline 0 & 21,29 & 20,33 & 18,21 & 19,96 \\
\hline 40 & 21,46 & 21,79 & 18,13 & 19,79 \\
\hline 80 & 21,63 & 21,13 & 18,79 & 20,04 \\
\hline 120 & 22,46 & 22,67 & 18,50 & 20,38 \\
\hline 160 & 22,25 & 22,04 & 18,92 & 19,38 \\
\hline Equação & $\mathrm{y}=21,82^{\mathrm{ns}}$ & $y=21,59^{\text {ns }}$ & - & - \\
\hline $\mathrm{R}^{2}$ & - & - & - & - \\
\hline \multicolumn{5}{|l|}{$\overline{\mathrm{K}_{2} \mathrm{O}}$} \\
\hline 0 & 20,53 & 20,95 & 18,48 & 19,95 \\
\hline 50 & 22,05 & 21,60 & 18,55 & 20,23 \\
\hline 100 & 22,88 & 22,23 & 18,50 & 19,83 \\
\hline Equação & $y=0,0235 x+0,64$ & $y=21,59^{\text {ns }}$ & - & - \\
\hline $\mathrm{R}^{2}$ & $0,97 * *$ & - & - & - \\
\hline Média & $21,82 \mathrm{a}$ & $21,59 \mathrm{a}$ & $18,51 b$ & $20,00 \mathrm{a}$ \\
\hline
\end{tabular}

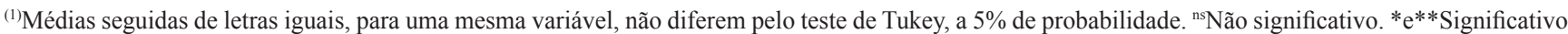
a 5 e $1 \%$ de probabilidade, respectivamente. Valores de F para a interação entres os fatores não foram significativos em nenhuma das safras. 
Tabela 5. Efeitos da aplicação de doses de fósforo e de potássio na germinação e no vigor de sementes de soja, de acordo com os diferentes testes avaliados na safra 2009/2010 e 2010/2011 (1).

\begin{tabular}{|c|c|c|c|c|c|c|c|c|}
\hline \multirow{2}{*}{$\begin{array}{l}\text { Dose } \\
\left(\mathrm{kg} \mathrm{ha}^{-1}\right)\end{array}$} & \multicolumn{2}{|c|}{ Teste padrão de germinação (\%) } & \multicolumn{2}{|c|}{ Envelhecimento acelerado (\%) } & \multicolumn{2}{|c|}{ Condutividade elétrica $\left(\mu \mathrm{S} \mathrm{cm}^{-1} \mathrm{~g}^{-1}\right)$} & \multicolumn{2}{|c|}{ Lixiviação de $\mathrm{K}\left(\mu \mathrm{g} \mathrm{g}^{-1}\right)$} \\
\hline & $2009 / 2010$ & $2010 / 2011$ & $2009 / 2010$ & $2010 / 2011$ & $2009 / 2010$ & $2010 / 2011$ & $2009 / 2010$ & $2010 / 2011$ \\
\hline \multicolumn{9}{|l|}{$\mathrm{P}_{2} \mathrm{O}_{5}$} \\
\hline 0 & 96,0 & 76,8 & 90,9 & 75,0 & 53,0 & 57,8 & 53,3 & 82,9 \\
\hline 40 & 93,2 & 81,8 & 87,8 & 78,6 & 57,9 & 58,0 & 54,3 & 95,0 \\
\hline 80 & 95,3 & 86,2 & 91,6 & 87,0 & 59,4 & 54,4 & 67,2 & 101,9 \\
\hline 120 & 95,0 & 77,8 & 90,7 & 69,3 & 55,0 & 57,3 & 54,6 & 109,4 \\
\hline 160 & 96,3 & 74,2 & 92,8 & 69,8 & 57,1 & 61,8 & 69,0 & 111,9 \\
\hline$\overline{\text { Equação }}$ & $\mathrm{y}=95,2^{\mathrm{ns}}$ & $\mathrm{y}=79,3^{\mathrm{ns}}$ & - & - & - & - & $\mathrm{y}=0,0792 \mathrm{x}+53,32$ & - \\
\hline $\mathrm{R}^{2}$ & - & - & - & - & - & - & $0,42 *$ & - \\
\hline \multicolumn{9}{|l|}{$\overline{\mathrm{K}_{2} \mathrm{O}}$} \\
\hline 0 & 92,6 & 82,1 & 87,5 & 79,5 & 57,5 & 57,1 & 56,4 & 99,7 \\
\hline 50 & 96,1 & 82,5 & 92,1 & 78,3 & 55,8 & 58,8 & 62,6 & 101,1 \\
\hline 100 & 96,8 & 73,4 & 92,7 & 70,1 & 56,1 & 57,7 & 60,0 & 99,8 \\
\hline Equação & $\mathrm{y}=0,0413 \mathrm{x}+93,09$ & $\mathrm{y}=79,3^{\mathrm{ns}}$ & - & - & - & - & - & - \\
\hline $\mathrm{R}^{2}$ & $0,87 * *$ & & - & - & - & - & - & - \\
\hline Média & $95,2 \mathrm{a}$ & $79,3 b$ & $90,8 \mathrm{a}$ & $75,9 b$ & $56,5 \mathrm{a}$ & $57,9 \mathrm{a}$ & $59,7 \mathrm{~b}$ & $100,2 \mathrm{a}$ \\
\hline
\end{tabular}

\section{Conclusões}

1. A adubação fosfatada aumenta a produtividade e não afeta a qualidade fisiológica das sementes de soja produzidas, mesmo em solo com disponibilidade muito baixa de fósforo.

2. A adubação potássica não afeta a produtividade nem altera o vigor das sementes de soja, mas pode melhorar a germinação, em solo com nível médio de potássio.

\section{Agradecimentos}

À Coordenação de Aperfeiçoamento de Pessoal de Nível Superior (Capes), pela concessão de bolsa.

\section{Referências}

BAALBAKI, R.Z.; ELIAS, S.G.; MARCOS FILHO, J.; MCDONALD, M.B. Seed vigor testing handbook. Ithaca: Association of Official Seed Analysts, 2009. 341p.

BANZATTO, D.A.; KRONKA, S. do N. Experimentação agrícola. 4.ed. Jaboticabal: FUNEP, 2006. 237p.

BEUTLER, A.N.; CENTURION, J.F.; CENTURION, M.A.P. da C.; FREDDI, O. da S.; SOUSA NETO, E.L. de; LEONEL, C.L.; SILVA, A.P. da. Traffic soil compaction of an oxisol related to soybean development and yield. Scientia Agricola, v.64, p.608-615, 2007. DOI: 10.1590/S0103-90162007000600008.

CENTURION, J.F. Caracterização e classificação dos solos da Faculdade de Ciências Agrárias e Veterinárias de Jaboticabal.
1998. 85p. Tese (Livre Docência) - Universidade Estadual Paulista, Jaboticabal.

CUSTÓDIO, C.C.; MARCOS FILHO, J. Potassium leachate test for the evaluation of soybean seed physiological quality. Seed Science and Technology, v.25, p.549-563, 1997.

FEHR, W.R.; CAVINESS, C.E. Stages of soybean development. Ames: Iowa State University of Science and Technology, 1977. $11 \mathrm{p}$.

FOLONI, J.S.S.; ROSOLEM, C.A. Produtividade e acúmulo de potássio na soja em função da antecipação da adubação potássica no sistema plantio direto. Revista Brasileira de Ciência do Solo, v.32, p.1549-1561, 2008. DOI: 10.1590/S0100-06832008000400019.

MARCOS FILHO, J.; VIEIRA, R.D. Eletrical conductivity test. In: BAALBAKI, R.; ELIAS, S.G.; MARCOS-FILHO, J.; MCDONALD, M.B. (Ed.). Seed vigor testing handbook. Ithaca: Association of Official Seed Analysts, 2009. p.186-199.

NUNES, A.S.; TIMOSSI, P.C.; PAVANI, M.C.M.O.D.; COSTA ALVES, A.P.L. Formação de cobertura vegetal e manejo de plantas daninhas na cultura da soja em sistema de plantio direto. Planta Daninha, v.28, p.727-733, 2010. DOI: 10.1590/ S0100-83582010000400004.

OLIBONE, D.; ROSOLEM, C.A. Phosphate fertilization and phosphorus forms in an Oxisol under no-till. Scientia Agricola, v.67, p.465-471, 2010. DOI: 10.1590/S0103-90162010000400014.

OLIVEIRA JÚNIOR, A. de; PROCHNOW, L.I.; KLEPKER, D. Soybean yield in response to application of phosphate rock associated with triple superphosphate. Scientia Agricola, v.68, p.376-385, 2011. DOI: 10.1590/S0103-90162011000300016.

PÁDUA, G.P. de; ZITO, R.K.; ARANTES, N.E.; FRANÇA NETO, J. de B. Influência do tamanho da semente na qualidade fisiológica e na produtividade da cultura da soja. Revista 
Brasileira de Sementes, v.32, p.9-16, 2010. DOI: 10.1590/ S0101-31222010000300001.

PARCIANELLO, G.; COSTA, J.A.; PIRES, J.L.F.; RAMBO, L.; SAGGIN, K. Tolerância da soja ao desfolhamento afetada pela redução do espaçamento entre fileiras. Ciência Rural, v.34, p.357-364, 2004. DOI: 10.1590/S0103-84782004000200004.

PEIXOTO, C.P.; CÂMARA, G.M. de S.; MARTINS, M.C.; MARCHIORI, L.F.S.; GUERZONI, R.A.; MATTIAZZI, P. Épocas de semeadura e densidade de plantas de soja: I. Componentes da produção e rendimento de grãos. Scientia Agricola, v.57, p.89-96, 2000. DOI: 10.1590/S0103-90162000000100015.

RABOY, V. Approaches and challenges to engineering seed phytate and total phosphorus. Plant Science, v.177, p.281-296, 2009. DOI: 10.1016/j.plantsci.2009.06.012.

RAIJ, B. van; ANDRADE, J.C. de; CANTARELLA, H.; QUAGGIO, J.A. (Ed.). Análise química para avaliação da fertilidade de solos tropicais. Campinas: Instituto Agronômico, 2001. 285p.

RAIJ, B. van; CANTARELLA, H.; QUAGGIO, J.A.; FURLANI, A.M.C. Recomendações de adubação e calagem para o Estado de São Paulo. 2.ed. Campinas: Instituto Agronômico, 1997. 285p. (IAC. Boletim técnico, 100).

REGRAS para análise de sementes. Brasília: Ministério da Agricultura, Pecuária e Abastecimento, 2009. 399p.

SALE, P.W.G.; CAMPBELL, L.C. Yield and composition of soybean seed as a function of potassium supply. Plant and Soil, v.96, p.317-325, 1986. DOI: 10.1007/BF02375136.

SANTOS, H.G. dos; JACOMINE, P.K.T.; ANJOS, L.H.C. dos; OLIVEIRA, V.A. de; OLIVEIRA, J.B. de; COELHO, M.R.; LUMBRERAS, J.F.; CUNHA, T.J.F. (Ed.). Sistema brasileiro de classificação de solos. 2.ed. Rio de Janeiro: Embrapa Solos, 2006. $306 \mathrm{p}$.

SERAFIM, M.E.; ONO, F.B.; ZEVIANI, W.M.; NOVELINO, J.O.; SILVA, J.V. Umidade do solo e doses de potássio na cultura da soja. Revista Ciência Agronômica, v.43, p.222-227, 2012. DOI: $10.1590 /$ S1806-66902012000200003.
TOLEDO, M.Z.; CASTRO, G.S.A.; CRUSCIOL, C.A.C.; SORATTO, R.P.; NAKAGAWA, J.; CAVARIANI, C. Physiological quality of soybean and wheat seeds produced with alternative potassium sources. Revista Brasileira de Sementes, v.33, p.363-371, 2011. DOI: 10.1590/S0101-31222011000200019.

UNIVERSIDADE ESTADUAL PAULISTA JÚLIO DE MESQUITA FILHO. Campus de Jaboticabal. Estação Agroclimatológica. Normais climatológicas. Disponível em: $<$ http://jaguar.fcav.unesp.br/portal_agromet/int_conteudo_sem img.php?conteudo=181>. Acesso em: 15 maio 2012.

VEIGA, A.D.; VON PINHO, É.V. de R.; VEIGA, A.D.; PEREIRA, P.H. de A.R.; OLIVEIRA, K.C. de; VON PINHO, R.G. Influência do potássio e da calagem na composição química, qualidade fisiológica e na atividade enzimática de sementes de soja. Ciência e Agrotecnologia, v.34, p.953-960, 2010. DOI: 10.1590/ S1413-70542010000400022.

VENTIMIGLIA, L.A.; COSTA, J.A.; THOMAS, A.L.; PIRES, J.L.F. Potencial de rendimento da soja em razão da disponibilidade de fósforo no solo e dos espaçamentos. Pesquisa Agropecuária Brasileira, v.34, p.195-199, 1999. DOI: 10.1590/ S0100-204X1999000200007.

VIEIRA, R.D.; SEDIYAMA, T.; CARVALHO, N.M. de; THIEBAUT, J.T.L.; SILVA, R.F. da; SEDIYAMA, C.S. Avaliação do efeito de doses de $\mathrm{P}$ e $\mathrm{K}$ na qualidade de sementes de soja. Revista Brasileira de Sementes, v.9, p.83-89, 1987.

VIEIRA, R.D.; TEKRONY, D.M.; EGLI, D.B; BRUENNING, W.P.; PANOBIANCO, M. Temperature during soybean seed storage and the amount of electrolytes of soaked seeds solution. Scientia Agricola, v.65, p.496-501, 2008. DOI: 10.1590/ S0103-90162008000500008.

ZUCARELI, C.; RAMOS JUNIOR, E.U.; BARREIRO, A.P.; NAKAGAWA, J.; CAVARIANI, C. Adubação fosfatada, componentes de produção, produtividade e qualidade fisiológica em sementes de feijão. Revista Brasileira de Sementes, v.28, p.9-15, 2006. DOI: 10.1590/S0101-31222006000100002.

Recebido em 22 de dezembro de 2012 e aprovado em 28 de junho de 2013

Pesq. agropec. bras., Brasília, v.48, n.7, p.783-790, jul. 2013

DOI: 10.1590/S0100-204X2013000700011 